\title{
Prevalence of Varicose Veins Among Secondary Schools' Teachers in Assiut Governorate
}

\author{
Ali L. Ali ${ }^{1}$, Safaa A.M.Kotb ${ }^{2}$, Ahmed H. Bakr ${ }^{3}$ \& Safaa R. Osman ${ }^{4}$. \\ 1. \\ High Qualified Nurse at Secondary Technical Nursing School at Dairout District, Egypt. \\ 2. Professor of Family \&Community Health Nursing, Faculty of Nursing, Assiut University, Egypt. \\ 3. \\ 4. \\ Assistant Professor of Vascular Surgery, Faculty of Medicine, Assiut University, Egypt. \\ Lecturer of Family \&Community Health Nursing, Faculty of Nursing, Assiut University, Egypt.
}

\begin{abstract}
Background: Varicose veins are chronic venous disorder described as enlarged, twisted, superficial veins caused by incompetent venous valves. It affects the lower limbs and quality of life of patients negatively. Aim: to determine the prevalence of varicose veins among secondary schools' teachers at Assiut Governorate. Methods: Descriptive cross sectional research design had been used. The study was conducted at 4 districts which were randomly selected by using simple random sample to select the schools ( 3 schools in each district). The total number of the study sample was 500 teachers. Tools: - Three tools were used; the first tool was a structured self-administered questionnaire for demographic data, medical history, and risk factors. The second tool Venous Insufficiency Epidemiological and Economic Study - symptoms (VEINES- Sym) questionnaire. The third tool was clinical examination and Arterial color coded duplex scanning. Results: Prevalence of varicose veins among secondary schools' teachers in Assiut Governorate was 25.6\%, 62.5\% of them are females while 37.5\% are males. Conclusion Varicose veins were widely spread among secondary schools' teachers in Assiut Governorate. Recommendations Health education program is very useful to prevent varicose veins and its complications.
\end{abstract}

\section{Keywords: Prevalence, Varicose Veins \& Teachers.}

\section{Introduction}

The teachers are the chief pillars of an advanced society. They responsible for the teaching and together with parents; they are the main source of knowledge and morals for children. There are a lot of problems faced by the teachers which have great effects on the lower limbs and quality of life. One of these problems is 'varicose veins' (Barnes et al., 2014).

Varicose veins (VV) are common chronic condition; they have been shown to adversely effects on patients' quality of life and major cause of morbidity as varicose veins can cause variety of symptoms ranging from itching to ulceration (Onida \& Davies, 2013).

Varicose veins are defined as "enlarged, usually twisted, subcutaneous veins $\geq 3 \mathrm{~mm}$ in diameter measured in the standing position with demonstrable reflux". Most commonly, this condition occurs in the lower extremities, the saphenous veins, or the lower trunk, but it can arise somewhere else in the body, such as the esophagus (Williams et al., 2013).

Varicose veins may be categorized according to clinical, etiological, anatomical, and pathophysiological classification into three types: primary, secondary, and congenital type. Many varicose veins are asymptomatic, and the patient's complaint purely cosmetic. When symptoms occur, they are often described as heaviness, aching, itching, swelling, restlessness and cramps (Vaidyanathan, 2015).

The etiology of varicose veins is until now incompletely understood even though the fact that it is a very common condition affecting all ages from teenagers to elderly people. There are several risk factors increase a person's chances of developing varicose veins, which include: hereditary, gender, increasing age, obesity, prolonged standing, pregnancy, history of leg injury or deep venous thrombosis (DVT) (Williams et al., 2013).

Management options for varicose veins consist of conservative management, external laser treatment, injection sclerotherapy, endovenous interventions, and surgery. Although VV are ordinarily benign, severe varicosities may lead to hazardous complications including edema, dermatitis, ulceration and unusual severe bleeding which is a life threatening condition. Furthermore, skin changes, such as hyperpigmentation, eczema, lipodermatosclerosis, and atrophie blanche may be occured (Wright \& Fitridge, 2013, Feliciano \& Dalsing, 2011). 
The best course of action is prevention, as varicose veins cannot be cured. some self-care measures that can help in the prevention are exercising regularly, maintaining a healthy body weight, avoiding constipation, eating a high-fiber, low-salt diet, avoiding tight clothing that constricts the legs, groin or waist, avoiding high heels and tight hosiery, changing the sitting or standing position regularly and avoiding long periods of standing or sitting, and avoiding crossing the legs when sitting. Also, shifting weight from one leg to the other every few minutes; when standing for long periods (Hinkle \& Cheever, 2013).

Nurses play a vital role in the care of cases with chronic venous diseases (CVDs). Although CVDs are common and spread all over the world, they are often underdiagnosed and, therefore, untreated. Therefore, nurses, who have the most frequent encounters with patients, are well positioned to make assessment for vulnerable patients and facilitate early diagnosis and early management. Community health nurse can act as caregiver, health educator, consultant, and researcher (Zhang \& Melander, 2014).

\section{Significance of the study}

Varicose veins are a common disease with a major socioeconomic effect because of its high prevalence. The cost of chronic venous disorders includes its investigations, its management, and the loss of working days of the affected patients (Milic, 2011 \& Cholewka, et al., 2017). In Egypt, there is no evidence research conducted about incidence and prevalence concerning varicose veins among teachers.

\section{Aim of the study}

The aim of the study is to:-

Determine the prevalence of varicose veins among secondary schools' teachers at Assiut Governorate.

\section{Research questions}

1. Are the teachers having high prevalence of varicose veins?

2. Is there a significant association between development of varicose vein and demographic variables of the teachers?

\section{Research design}

Descriptive - cross sectional research design was used in this study.

\section{I-Technical design}

\section{Setting of the study}

The study was conducted at 4 districts were randomly selected (Dairout, El kousia, Assiut and Abutig). 12 secondary schools were included in this study.

\section{Sampling}

Simple random sample was used in this study to select the schools (3 schools in each district). The total number of secondary schools' teachers in Assiut Governorate was 3901 teachers. Sample size was calculated using the previous prevalence of varicose veins in the Qassim Region in Saudi Arabia which represented $61.1 \%$ (Al Shammeri, et al., 2014) with software Epi/Info version 7 with $97 \%$ confidence level and power $80 \%$ of the test. It was found to be 465 teachers which increased to 500 to safeguard against non-response 125 teachers from each district were been selected.

\section{Tools of data collection}

Tool (1): Self-administered questionnaire sheet which included two parts

Portion 1: Personal characteristics of the teachers such as; name, age, sex, marital status, height, weight, years of experience, residence and working hours / week. Body mass index (BMI) was calculated according to (WHO 2015), via the subsequent equation:

BMI = weight in kilograms / (height in metres $)^{2}$. It was categorized as:

1) Underweight: $<18.5 \mathrm{~kg} / \mathrm{m} 2$.

2) Normal weight, $18.5-24.99 \mathrm{~kg} / \mathrm{m} 2$.

3) Overweight; 25 to $<30 \mathrm{~kg} / \mathrm{m} 2$.

4) Obese, $\geq 30 \mathrm{gfd} \mathrm{kg} / \mathrm{m} 2$.

Portion 2: Risk factors and treatment of varicose veins adopted from Edinburgh vein study questionnaire (Robertson, 2013). Risk factors such as age, gender, smoking...etc, and treatment such as compression therapy, surgery, sclerotherapy...etc.

Tool (2)

Venous Insufficiency Epidemiological and Economic Study - symptoms (VEINES/ Sym) questionnaire used to assess symptoms of varicose veins (Tuygun et al., 2012).

The VEINES /Sym comprises of ten items which are associated with the symptoms of VV. The time considered for questions related to symptoms covers the last four weeks (Bland et al., 2015).

The score produced by VEINES-Sym includes ten items which are associated with the following symptoms: heavy legs, sore legs, swelling, night cramps, heat or burning sensation, restless legs, throbbing, itching and numbness. Such symptoms are assessed by a five-point Likert scale (every day $=1$, several times a week $=2$, about once a week $=3$, less than once a week $=4$, never $=5$ ), related to their frequency. The further item, is associated with discomfort in the legs and is evaluated as to its intensity by a six-point Likert scale (very severe $=1$, severe $=2$, moderate $=3$, mild $=4$, very mild $=5$, none 
$=6$ ). Higher scores indicate better outcomes (Méan et al., 2014, Migdalski \& Kuzdak, 2015).

Validity test

The validity was tested for content validity by the jury of five experts in the field of medical and nursing sciences. Their comments were reviewed and the necessary modifications were done.

\section{Reliability test}

Reliability was applied by the researchers for testing the internal consistency of the tool. Cranach's Alpha reliability was 0.924 for VEINS/ sym.

Tool (3): Clinical examination and Hand-Held Doppler has been done to make accurate diagnosis for teachers who complain from any symptoms of varicose vein.

\section{Pilot study:}

A pilot study was carried out on 20 teachers (included in the studied sample because there weren't any modifications). Its purpose is to assess the feasibility of the study and clarity of the data collection tools. It also helped to estimate the time needed for filling the forms.

\section{II-Operational design}

Data collection procedure was carried out in two phases

\section{Phase 1: preparatory phase}

It includes reviewing of current literature in the various aspects of the review using textbooks, articles, different studies, internet and journals in order to develop the study tools for data collection.

\section{Phase 2: Implementation phase (Field work)}

Data were collected from teachers working in secondary Schools at 4 districts (Dairout, El kousia, Assiut and Abutig). The purpose of the study was explained to the teachers prior for answering the questions. The study was carried out during morning for all available teachers. The sheet was filled out individualized with the teachers and was distributed to be answered then collected. Data collection started from May/2016 to October/ 2016, through three days per week randomly. Data collection was been stopped through final Secondary School Examinations from 5: 28 June.

\section{Leg examination}

After questionnaires were been collected and checked by research staff, all participants were been categorized as:

- Teachers who had neither any leg problems nor any signs or symptoms of varicose veins (333 teachers):they excluded from leg examination, quality of life of them were been measured and used as a "control group".

- Teachers who had been already diagnosed with varicose veins by a specialist doctor (124 teachers):their knowledge about practice and compliance with treatment were been assessed, and their quality of life were been measured and used as a "study group".

- Teachers who had any signs or symptoms of varicose veins but had not been already diagnosed with varicose veins by a specialist doctor (43 teachers), they had been referred to leg examination with handheld Doppler. Four teachers of them had been already diagnosed with varicose veins; they had been excluded from reported practices and treatment.

\section{III- Administrative design}

An official approval letter was obtained from Dean of Nursing Faculty, Assiut University to Undersecretary Ministry of Education in Assiut governorate to obtain the necessary approval for conducting the study. This letter included a permission to collect the necessary data and explain the purpose and nature of the study.

\section{Ethical consideration}

1- Approval for research proposal has been done from ethical committee in the Faculty of Nursing.

2- There is no hazard for selected teachers in the course of application of the research.

3- The study was followed common ethical principles in clinical research.

4- Oral agreement was attained from teachers who participated in the study, after clarifying the nature and purpose of the study

5- Teachers were guaranteed that the data of his research will not be reused without second permission.

6- Confidentiality and anonymity were assured.

IV-Statistical Analysis

- Obtained data were reviewed, organized for computer entry, coded, analyzed and tabulated. Descriptive statistics (i.e., percentage, mean, standard deviation, etc) was done by computer program SPSS version 20.

- Chi-square test used to compare differences in the distribution of frequencies among different groups. It is considered * significant when $\mathrm{P}$ values were less than 0.05 or $(\mathrm{P}<0.05)$. 


\section{Results}

Table (1): Distribution of studied secondary schools' teachers according to their personal data in Assiut Governorate, 2016 (No. = 500).

\begin{tabular}{|c|c|c|}
\hline Characteristics & $($ No. $=500)$ & $\%$ \\
\hline \multicolumn{3}{|l|}{ Age group } \\
\hline 25-34 year & 146 & 29.2 \\
\hline 35-44 year & 207 & 41.4 \\
\hline $45-55$ year & 122 & 24.4 \\
\hline$>55$ year & 25 & 5.0 \\
\hline \multicolumn{3}{|l|}{ Gender } \\
\hline Male & 263 & 52.6 \\
\hline Female & 237 & 47.4 \\
\hline \multicolumn{3}{|l|}{ Residence } \\
\hline Urban & 269 & 53.8 \\
\hline Rural & 231 & 46.2 \\
\hline \multicolumn{3}{|l|}{ Marital Status } \\
\hline Single & 39 & 7.8 \\
\hline Married & 440 & 88.0 \\
\hline Widowed & 21 & 4.2 \\
\hline \multicolumn{3}{|l|}{ Years of experience } \\
\hline$<10$ years & 122 & 24.4 \\
\hline $10-20$ & 88 & 17.6 \\
\hline$>20$ & 290 & 58.0 \\
\hline \multicolumn{3}{|l|}{ Body Mass Index } \\
\hline Normal weight & 140 & 28.0 \\
\hline Overweight & 208 & 41.6 \\
\hline Obese & 152 & 30.4 \\
\hline \multicolumn{3}{|l|}{ Number of lessons (shares) } \\
\hline$<10$ lessons (shares) per month & 80 & 16.0 \\
\hline 10-20 lessons (shares) per month & 405 & 81.0 \\
\hline$>20$ lessons (shares) per month & 15 & 3.0 \\
\hline \multicolumn{3}{|l|}{ Duration of lesson (share) } \\
\hline $40-45$ minutes & 299 & 59.8 \\
\hline $45-50$ minutes & 165 & 33.0 \\
\hline 50- 55 minutes & 36 & 7.2 \\
\hline
\end{tabular}

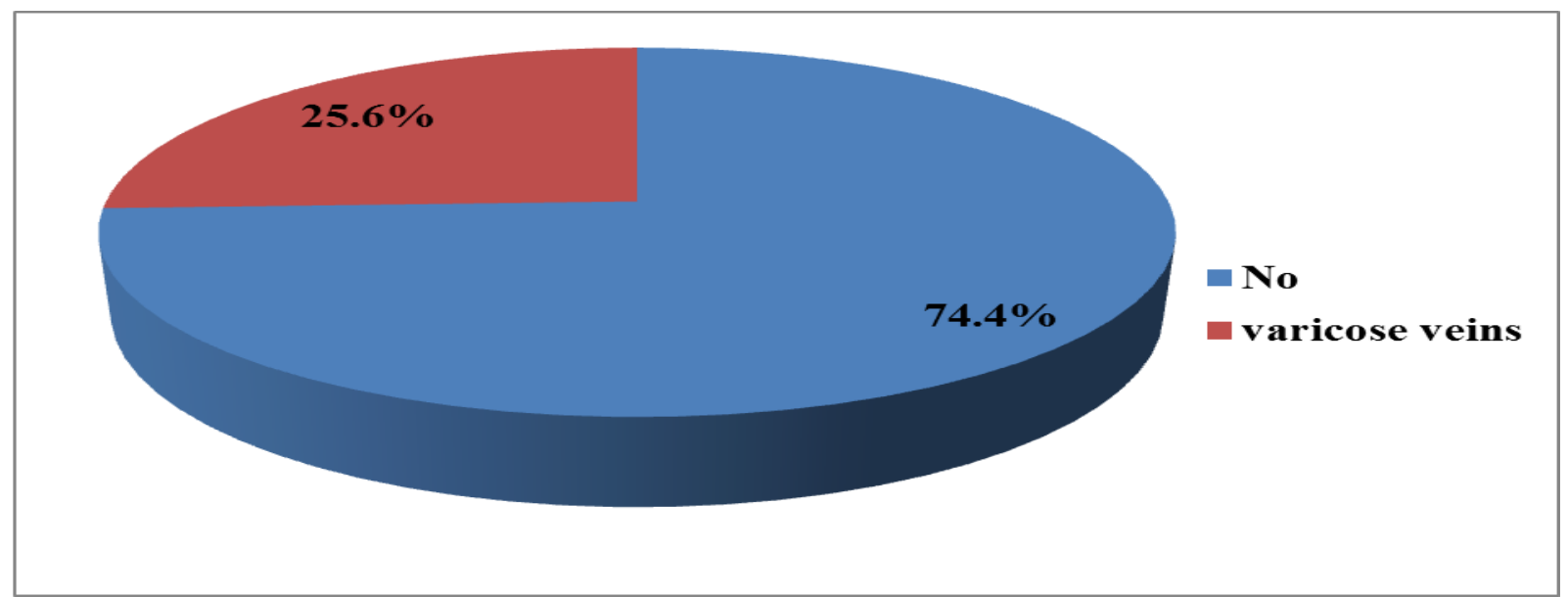

Figure (1): Prevalence of varicose veins among studied secondary schools' teachers in Assiut Governorate, (2016). 
Table (2): Relationship between varicose veins and personal data of secondary schools' teachers in Assiut Governorate, (2016).

\begin{tabular}{|c|c|c|c|c|c|}
\hline & \multicolumn{2}{|c|}{$\begin{array}{c}\text { Affected with Varicose } \\
\text { Veins }\end{array}$} & \multicolumn{2}{|c|}{$\begin{array}{l}\text { non-affected with Varicose } \\
\text { Veins }\end{array}$} & \multirow[t]{2}{*}{ P. value } \\
\hline & No. $=128$ & $\%$ & No. $=372$ & $\%$ & \\
\hline \multicolumn{5}{|l|}{ Gender } & \multirow[b]{3}{*}{$0.000 * *$} \\
\hline Male & 48 & 37.5 & 215 & 57.8 & \\
\hline Female & 80 & 62.5 & 157 & 42.2 & \\
\hline \multicolumn{5}{|l|}{ Age groups } & \multirow{5}{*}{$0.006^{* *}$} \\
\hline 27-34 year & 23 & 18 & 123 & 33.1 & \\
\hline $35-44$ year & 69 & 53.9 & 138 & 37.1 & \\
\hline $45-55$ years & 19 & 14.8 & 103 & 27.6 & \\
\hline$>55$ year & 17 & 13.3 & 8 & 2.2 & \\
\hline \multicolumn{5}{|l|}{ Residence } & \multirow{3}{*}{$<0.001 * *$} \\
\hline Rural & 38 & 29.7 & 193 & 51.9 & \\
\hline Urban & 90 & 70.3 & 179 & 48.1 & \\
\hline \multicolumn{5}{|l|}{ Marital Status } & \multirow{4}{*}{0.072} \\
\hline Single & 4 & 3.1 & 35 & 9.4 & \\
\hline Married & 118 & 92.2 & 322 & 86.6 & \\
\hline Widow & 6 & 4.7 & 15 & 4.0 & \\
\hline \multicolumn{5}{|l|}{ Years of experience } & \multirow{4}{*}{$<0.001 * *$} \\
\hline$<10$ years & 15 & 11.7 & 107 & 28.8 & \\
\hline $10-20$ & 31 & 24.2 & 57 & 15.3 & \\
\hline$>20$ & 82 & 64.1 & 208 & 55.9 & \\
\hline \multicolumn{5}{|l|}{ BMI groups } & \multirow{4}{*}{$<0.001 * *$} \\
\hline Normal weight & 15 & 11.7 & 125 & 33.6 & \\
\hline Overweight & 36 & 28.1 & 172 & 46.2 & \\
\hline Obese & 77 & 60.2 & 75 & 20.2 & \\
\hline
\end{tabular}

Table (3): Relationship between Varicose Veins and risk factors of affected and non-affected secondary schools' teachers in Assiut Governorate, 2016.

\begin{tabular}{|c|c|c|c|c|c|}
\hline \multirow[t]{2}{*}{ Risk factors } & \multicolumn{2}{|c|}{$\begin{array}{c}\text { Affected with Varicose } \\
\text { Veins }\end{array}$} & \multicolumn{2}{|c|}{$\begin{array}{l}\text { non-affected with } \\
\text { Varicose Veins }\end{array}$} & \multirow[t]{2}{*}{ P. value } \\
\hline & No. $=128$ & $\%$ & No. $=372$ & $\%$ & \\
\hline \multicolumn{5}{|l|}{ Regular physical exercises } & \multirow{3}{*}{$<0.001 * *$} \\
\hline Yes & 71 & 55.5 & 307 & 82.5 & \\
\hline No & 57 & 44.5 & 65 & 17.5 & \\
\hline \multicolumn{6}{|l|}{ Chronic diseases \# } \\
\hline Diabetes Mellitus & 19 & 14.8 & 74 & 19.9 & 0.205 \\
\hline Hypertension & 33 & 25.8 & 58 & 15.6 & $0.010 *$ \\
\hline Cardiac diseases & 16 & 12.5 & 15 & 4.0 & $0.001 * *$ \\
\hline Chronic renal disease & 15 & 11.7 & 5 & 1.3 & $0.000 * *$ \\
\hline Chronic liver disease & 1 & 0.8 & 15 & 4.0 & 0.071 \\
\hline None & 75 & 58.6 & 238 & 64.0 & 0.277 \\
\hline \multicolumn{5}{|l|}{ Smoking } & \multirow{3}{*}{0.691} \\
\hline Yes & 19 & 14.8 & 50 & 13.4 & \\
\hline No & 109 & 85.2 & 322 & 86.6 & \\
\hline \multicolumn{5}{|l|}{ Negative smoking } & \multirow{3}{*}{0.692} \\
\hline Yes & 69 & 53.9 & 193 & 51.9 & \\
\hline No & 59 & 46.1 & 179 & 48.1 & \\
\hline
\end{tabular}




\begin{tabular}{|c|c|c|c|c|c|}
\hline \multirow[t]{2}{*}{ Risk factors } & \multicolumn{2}{|c|}{$\begin{array}{c}\text { Affected with Varicose } \\
\text { Veins }\end{array}$} & \multicolumn{2}{|c|}{$\begin{array}{l}\text { non-affected with } \\
\text { Varicose Veins }\end{array}$} & \multirow[t]{2}{*}{ P. value } \\
\hline & No. $=128$ & $\%$ & No. $=372$ & $\%$ & \\
\hline \multicolumn{5}{|l|}{ Physical activities } & \multirow{3}{*}{$0.0384 *$} \\
\hline Standing for long periods & 102 & 79.7 & 261 & 70.2 & \\
\hline Sitting for long periods & 26 & 20.3 & 111 & 29.8 & \\
\hline \multicolumn{5}{|l|}{ Family history } & \multirow{3}{*}{$<0.0001 * *$} \\
\hline Yes & 75 & 58.6 & 17 & 4.6 & \\
\hline No & 53 & 41.4 & 355 & 95.4 & \\
\hline \multicolumn{5}{|l|}{ Wearing tight clothes } & \multirow{3}{*}{$0.003 * *$} \\
\hline Yes & 16 & 12.5 & 17 & 13.3 & \\
\hline No & 112 & 87.5 & 355 & 86.7 & \\
\hline \multicolumn{5}{|l|}{ Wearing high heel shoes } & \multirow{3}{*}{$<0.001 * *$} \\
\hline Yes & 34 & 26.6 & 27 & 7.3 & \\
\hline No & 94 & 73.4 & 345 & 92.7 & \\
\hline Taking oral contraceptive No. $=237$ & $80 *$ & & & & \multirow{3}{*}{0.276} \\
\hline Yes & 20 & 25 & 50 & 31.8 & \\
\hline No & 60 & 75 & 107 & 68.2 & \\
\hline \multicolumn{5}{|l|}{ Number of pregnancies $(\mathrm{N}=\mathrm{80})$} & \multirow{3}{*}{$<0.001 * *$} \\
\hline$\leq 3$ & 37 & 46.2 & 72 & 47.1 & \\
\hline$>3$ & 43 & 53.8 & 81 & 52.9 & \\
\hline
\end{tabular}

* total number of affected female teachers

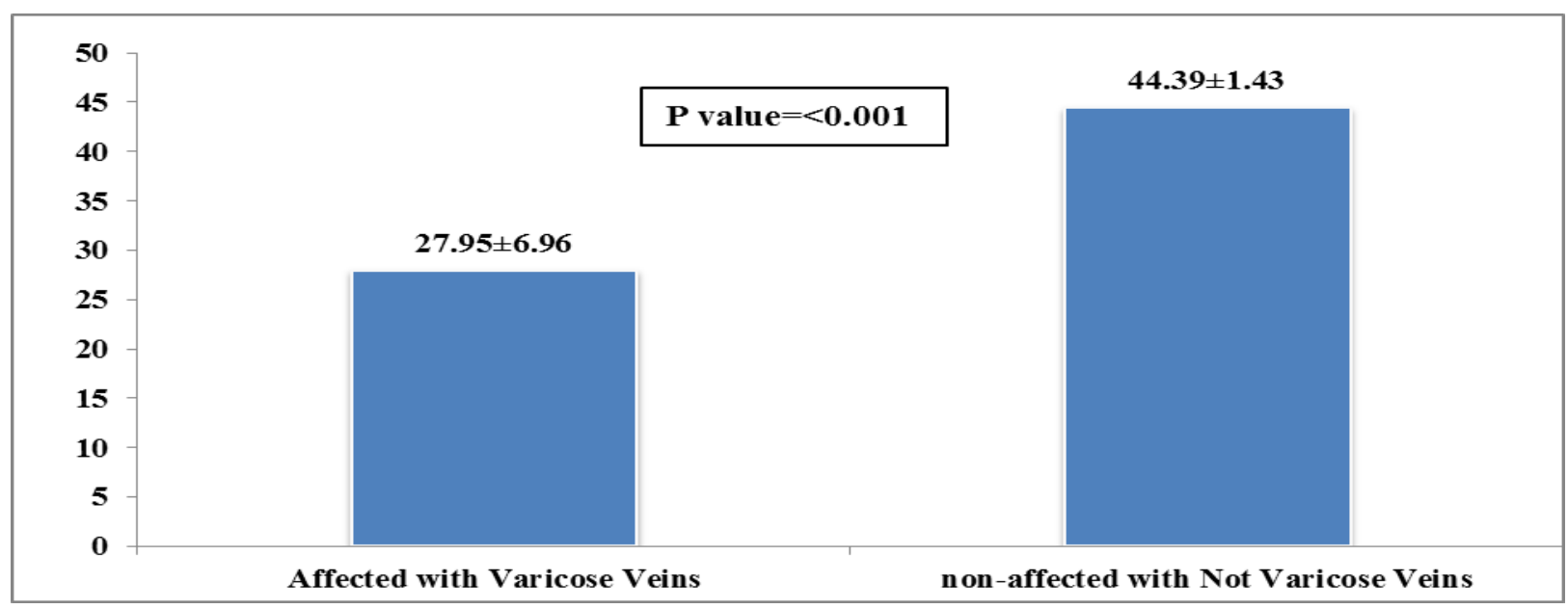

Figure (2): Relationship between mean scores of VEINES/ Symptoms of affected and non-affected secondary schools' teachers in Assiut Governorate, (2016).

Table (1): Showed that more than two fifth $(41.4 \%)$ of teachers aged 35- 44 years, also $52.6 \%$ were males, and $53.8 \%$ were living in urban area. Regarding their marital status $88.0 \%$ of the studied sample was married. According to years of experience, more than half $(58.0 \%)$ of them were had more than 20 years. Regarding the weight $28 \%$ of teachers are normal weight, $41.6 \%$ are overweight while $30.4 \%$ are obese. Also, this table revealed that
$81 \%$ of studied teachers had $10-20$ lessons (shares) per month.

Table (2): Show that there is statistically significant relationship between varicose veins and gender, age, residence, years of experience and BMI, however there is no significant relationship between varicose veins and marital status.

Table (3): Showed that there was a statistical significant relationship between varicose veins and physical exercises, positive family history, standing 
for long periods, wearing tight clothes and high heel shoes and number of pregnancies, however there was no statistical significant relationship between varicose veins and smoking and taking oral contraceptive pills.

Figure (1): Showed that slightly more than quarter of studied teachers $(25.6 \%)$ had varicose veins.

Figure (2): Showed that the mean of total symptoms score for affected and non-affected secondary schools' teachers was $(27.95 \pm 6.96$ and $44.39 \pm 1.43)$ respectively. Also, it cleared that there was a statistical significant relationship $(\mathrm{P}$ value $=<0.001)$ between the mean of total score of VEINES/ Symptoms among affected and non-affected secondary schools' teachers.

\section{Discussion}

Chronic varicose veins can negatively affect the lives of the affected people, especially who usually stand for long periods on their feet especially the surgeons, nursing staff, traffic worker and teachers (Barnes et al., 2014).

The findings of this study revealed that mean age of studied sample were $45.11 \pm 9.09$ and $41.4 \%$ of participants age ranged from 35- 44 years. These findings are consistent with a study about prevalence of CVI in the Qassim Region and effect of compression stockings which conducted by Al Shammeri et al., (2014) who found that the average age of participants is 43.8 years.

According to gender, the present study illustrated that more than half of studied sample were males, while less than half of them were females. This inconsistence with a study about Generic Healthrelated Quality of Life is significantly worse in Varicose Vein Patients conducted by Darvall et al., (2012) who found that less than two thirds of studied sample were females, while other third were males.

According to the residence, the results of this study demonstrated that more than half of the studied sample were from urban area. These findings are consistent with a study carried by Joseph et al, 2016 about A multicenter review of epidemiology and management of varicose veins for national guidance, who find that about two thirds of the studied sample were from urban area.

Regarding Body Mass Index (BMI), the findings of this study demonstrated that more than more than two thirds of studied sample are overweight and obese. This may be due to unhealthy eating habits and increased rate of obesity in Egypt. These findings inconsistence with a study about Prevalence, risk and aggravating factors of chronic venous disease of the general population of Greece carried by Dimakakos et al., (2013) which revealed that more than half of studied sample are normal weight.

Regarding marital status, the findings of the present study showed that more than three quarters of the studied sample were married. These findings are consistent with Joseph et al., (2016) who found that more than three quarters of the studied sample were married.

According to years of experience, the results of this study showed that more than half of the studied sample have more than 20 years of experience. These findings are agreed with a study about Varicose veins in hairdressers and associated risk factors, conducted by Chen \& Guo, (2014) who found that increased years of experience was major risk factor for developing varicose veins.

The current study illustrated that the prevalence of varicose veins among secondary schools' teachers was high as slightly more than quarter of the studied sample had varicose veins, this may be due to long periods of standing at their occupation beside other risk factors as (number of pregnancies, physical activities, wearing tight clothes and high heel shoes). This result was consistence with Chen \& Guo, (2014) who found that about one quarter of the studied sample had lower limb VV.

As regard to gender, it was demonstrated that prevalence of varicose veins in women was higher than men. This may be due to risk factors as hormonal factors in women, the daily activities, pregnancy, age, obesity and heredity factors. This result was consistence with Dimakakos et al., (2013) who found that prevalence of varicose veins in women was higher than men was.

The current study illustrated that there was a statistically significant relationship between varicose veins and $(\mathrm{BMI}) \mathrm{p}=0.00)$, this may be due to the increased load on the $\operatorname{leg}(\mathrm{s})$, and gradually lead to venous incompetence. This result was consistence with Dimakakos et al., (2013) while, these findings were incongruenced with Chen \& Guo, (2014) who revealed that the body mass index (BMI) did not seem to be significant risk factor of lower limb VV $(\mathrm{p}>0.05)$.

The current study showed that there was a statistically significant relationship between varicose veins and years of experience, $(p=0.006)$. This may be due to an older age and more hours of standing in working. This result was consistence with Chen \& Guo, (2014) who revealed that In contrast with hairdressers without the disorder, those who had VV had a longer years of experience (the number of years of working as a hairdresser was 30.5 vs. 24.0 years, $\mathrm{p}=0.005)$. 
The findings of this study demonstrated that there was a statistically significant relationship between varicose veins and positive family history, $\mathrm{p}<0.001$ ). This result was consistence with Chen \& Guo, (2014) \& Robertson, 2013 who showed that there was a statistically significant relationship between varicose veins and positive family history, as ( $\mathrm{p}=$ $0.011 \& 0.009)$ respectively. Although, this finding was inconsistent with Kohno, et al., (2014) who found that there was statistically not significant relationship between varicose veins and positive family history, $\mathrm{p}=0.783$ ).

The findings of this study revealed that there was a statistically significant relationship between varicose veins and regular physical exercises. This may be due to regular exercise strengthen the calf muscle and thus help veins' competence. This result was disagreed with Chen \& Guo, (2014) who showed that there was a statistically not significant relationship between varicose veins and regular physical exercise $(p=0.607)$.

The findings of this study demonstrated that there was a statistically significant relationship between varicose veins and physical activities per day; the prevalence of $\mathrm{VV}$ among studied sample who standing for long periods was more than that who sitting for long periods $(\mathrm{p}=0.0384)$. This may be due to standing for long times increases the venous pressure in the leg veins as a consequence of the hydrostatic effect that occurs in the upright position, so the vein wall come to be gradually dilated and elastic, thus resulting in valvular impairment and incompetence. This result was agreed with Chen \& Guo, (2014).

According to the current study, there was a statistically significant relationship between varicose veins and number of pregnancies; as women who had more than three pregnancies had more prevalence rate of $\mathrm{VV}$ than who had three pregnancies or less $(\mathrm{p}<0.001)$. This may be due to increases in progesterone production during pregnancy cause the vein walls to dilate and become less elastic. Also, increasing of intra-abdominal pressure, in combination with the pressure of the uterus on the iliac veins through pregnancy, hinders venous return from the lower limb. These lead to rupture of venous valves, reflux develops and varicose veins occur.

\section{Conclusion}

Based on the present study findings and research questions, it was concluded that

- Varicose veins are widely spread among secondary schools' teachers (more than one quarter) in Assiut Governorate.
- There were gender differences in the prevalence; it more prevalent in women than men.

- Gender, age, residence, years of experience, BMI, family history, physical exercises, and physical activities especially standing for long periods are considered risk factors of varicose veins.

\section{Recommendation}

The current study suggested recommendations included the following:

Based on the results of this study it was recommended that

- Health education programs should be implemented for increasing awareness of teachers to prevent varicose vein and its consequences.

Further researches; by using a greater sample size, are needed to assess the incidence rate of varicose veins among all risk groups because it may be a symptomatic and patients complained only from cosmetic appearance of the lower limb veins.

\section{References}

1. Al Shammeri O., AlHamdan N., Al-Hothaly B., Midhet F., Hussain M., \& Al-Mohaimeed A., (2014): Chronic Venous Insufficiency: prevalence and effect of compression stockings. International journal of health sciences, v 8(3), Pp 231.

2. Barnes A., Gireesh G., Sachina B., \& Raiju P., (2014): Effectiveness of Self Instructional Module (SIM) on Knowledge regarding the Prevention and Management of Varicose Veins among Teachers in Selected Schools of Udupi district. Asian Journal of Nursing Education and Research, V. 4(4), 452.

3. Bland J., Dumville J., Ashby R., Gabe R., Stubbs N., Adderley \& Cullum N., (2015): Validation of the VEINES-QOL quality of life instrument in venous leg ulcers: repeatability and validity study embedded in a randomised clinical trial. BMC cardiovascular disorders, V 15(1), P 85.

4. Chen C., \& Guo H., (2014): Varicose veins in hairdressers and associated risk factors: a crosssectional study. BMC public health, v 14(1), P 885.

5. Chong E., \& Chan A., (2010): Subjective health complaints of teachers from primary and secondary schools in Hong Kong. International journal of occupational safety and ergonomics, $v$ 16(1), Pp 23-39.

6. Darvall K., Bate G., Adam D., \& Bradbury A., (2012): Generic health-related quality of life is significantly worse in varicose vein patients with 
lower limb symptoms independent of CEAP clinical grade. European Journal of Vascular and Endovascular Surgery, v 44(3), Pp 341-344.

7. Dimakakos E., Syrigos K., Scliros E., Karaitianos I., (2013): Prevalence, risk and aggravating factors of chronic venous disease: an epidemiological survey of the general population of Greece. Phlebology.; v 28(4): Pp 184-90.

8. Feliciano B., \& Dalsing M., (2011): Varicose vein: current management. Advances in surgery, $v$ 45(1), Pp 45- 62.

9. Hinkle J., \& Cheever K., (2013): Brunner \& Siddhartha's Textbook of Medical-Surgical Nursing (13th ed.), Assessment and management of patients with vascular disorders and peripheral circulation, Philadelphia: Lippincott Williams \& Wilkins, chapter 30, pp.1807-1810.

10. Joseph N., Abhishai B., Thouseef M., Devi U., Abna A., \& Juneja I., (2016): A multicenter review of epidemiology and management of varicose veins for national guidance. Annals of medicine and surgery, $v 8, \mathrm{Pp} 21-27$.

11. Kohno K., Niihara H., Hamano T., Takeda M., Yamasaki M., Mizumoto K., \& Shiwaku K., (2014): Standing posture at work and overweight exacerbate varicose veins: Shimane CoHRE Study. The Journal of dermatology, v 41(11), Pp 964-968.

12. Mallick R., Lal B., \& Daugherty C., (2017): Relationship between patient-reported symptoms, limitations in daily activities, and psychological impact in varicose veins. Journal of Vascular Surgery: Venous and Lymphatic Disorders, $v$ 5(2), Pp 224-237.

13. Méan M., Limacher A., Kahn S., \& Aujesky D., (2014): The VEINES-QOL/Sym questionnaire is a reliable and valid diseasespecific quality of life measure for deep vein thrombosis in elderly patients. Quality of life research, $v$ 23(9), Pp 2463-2471.

14. Migdalski L., \& Kuzdak K., (2015): The Use of The VEINES-QOL/Sym Questionnaire In Patients Operated For Varicose Veins. Polish Journal of Surgery,v 87(10), Pp 491-498.

15. Moura R., Goncalves G., Navarro T., Britto R., Dias R., (2011): Transcultural adaptation of VEINES/QOL-Sym questionnaire: evaluation of quality of life and symptoms in chronic venous disease. J Vasc Bras. V 10: Pp 17-25.

16. Onida S., \& Davies A., (2013): Varicose veins: diagnosis and management. Nursing Times; 109: 41, 16-17.

17. Robertson L., (2013): Incidence of varicose veins, chronic venous insufficiency and venous reflux in the general population and associated risk factors: The Edinburgh Vein Study Follow Up by,pp.1-436.Retrievedfrom https://www.era.lib.ed.ac.uk/bitstream/1842/8149/ 2/ Robertson 2013.

18. Tuygun A., Ketenci B., Gunay R., Gorur A., Guney M., Bicer M., (2012): Validity and reliability of VEINES-QOL/Sym questionnaire in chronic venous disorders. Journal of Cardiovasc Surg. V 53: Pp 355-361.

19. Vaidyanathan S., (2015): Chronic Venous Disorders: Classification, Severity Assessment, and Nomenclature. In Chronic Venous Disorders of the Lower Limbs (pp. 25-32). Springer India.

20. Vuylsteke M., Thomis S., Guillaume G., Modliszewski M., Weides N., \& Staelens I., (2015): Epidemiological study on chronic venous disease in Belgium and Luxembourg: prevalence, risk factors, and symptomatology. European Journal of Vascular and Endovascular Surgery, V 49(4), Pp 432-439.

21. Williams N., Christopher J., Bulstrode, \& O'Connell P., (2013): Bailey \& Love's Short Practice of Surgery 26E. Crc Press.Pp. 910: 922.

22. World Health Organization (WHO). (2015): World Health Organization. Obesity and overweight. Fact sheet N 3112015 [updated January 2015].

23. Wright N., \& Fitridge R., (2013): Varicose veins: Natural history, assessment and management. Australian family physician, $v$ 42(6), Pp 380.

24. Zhang S., \& Melander S., (2014): Varicose Veins: Diagnosis, Management, and Treatment. The Journal for Nurse Practitioners, v. 10(6), Pp 417-424. 